TITLE:

\title{
Rhynchothorax mediterraneus, the First Record of Rhynchothoracidae (Pycnogonida) from Japan
}

AUTHOR(S):

Miyazaki, Katsumi; Stock, Jan H.

CITATION:

Miyazaki, Katsumi ... [et al]. Rhynchothorax mediterraneus, the First Record of

Rhynchothoracidae (Pycnogonida) from Japan. PUBLICATIONS OF THE SETO MARINE BIOLOGICAL LABORATORY 1995, 36(5-6): 325-327

ISSUE DATE:

1995-07-31

URL:

http://hdl.handle.net/2433/176248

RIGHT: 


\title{
Rhynchothorax mediterraneus, the First Record of Rhynchothoracidae (Pycnogonida) from Japan
}

\author{
Katsumi Miyazaki \\ Seto Marine Biological Laboratory, Kyoto University, \\ Shirahama, Wakayama 649-22, Japan \\ and \\ JAN H. STOGK \\ c/o Institute of Systematics and Population Biology, \\ University of Amsterdam, P.O. Box 94766, 1090 GT Amsterdam, \\ The Netherlands \\ With Text-figures $1-2$
}

\begin{abstract}
Several specimens of a pycnogonid, Rhynchothorax mediterraneus Costa, 1861 were found in collections from Tanabe Bay. This is the first record of the family Rhynchothoracidae from Japanese waters and considerably extends the species' distribution.
\end{abstract}

\section{Introduction}

The Japanese pycnogonid fauna is extremely rich with over 155 species covering most of the families (Nakamura and Child, 1991). The only exception is the family Rhynchothoracidae although some authors believe the presence of it in Japanese waters (Krapp, 1973; Nakamura and Child, 1991).

We report the first Japanese member of this family, Rhynchothorax mediterraneus from Tanabe Bay, on the Pacific coast of southwestern Japan.

\section{Rhynchothorax mediterraneus Costa, 1861}

\section{(Figure 1)}

Child 1988: 56 (references); Stock 1988: 507; Arnaud \& Krapp 1990: 4-5(key); Stock 1992: 135-136; Stock 1994: 41.

\section{Materials}

1 female, off Minabe, Tanabe Bay, depth unknown, on calcareous algae, 30 March 1994; 2 males, 3 females, off Minabe, Tanabe Bay, depth unknown, on stony and soft corals, 25 April 1994.

All materials were found among the private collection of Mr. Atsushi Mori, Seto Marine Biological Laboratory, taken from wastes of hauls of spiny lobster fishing off Minabe.

\section{Remarks}

Publ. Seto Mar. Biol. Lab., 36(5/6), 325-327, 1995. 


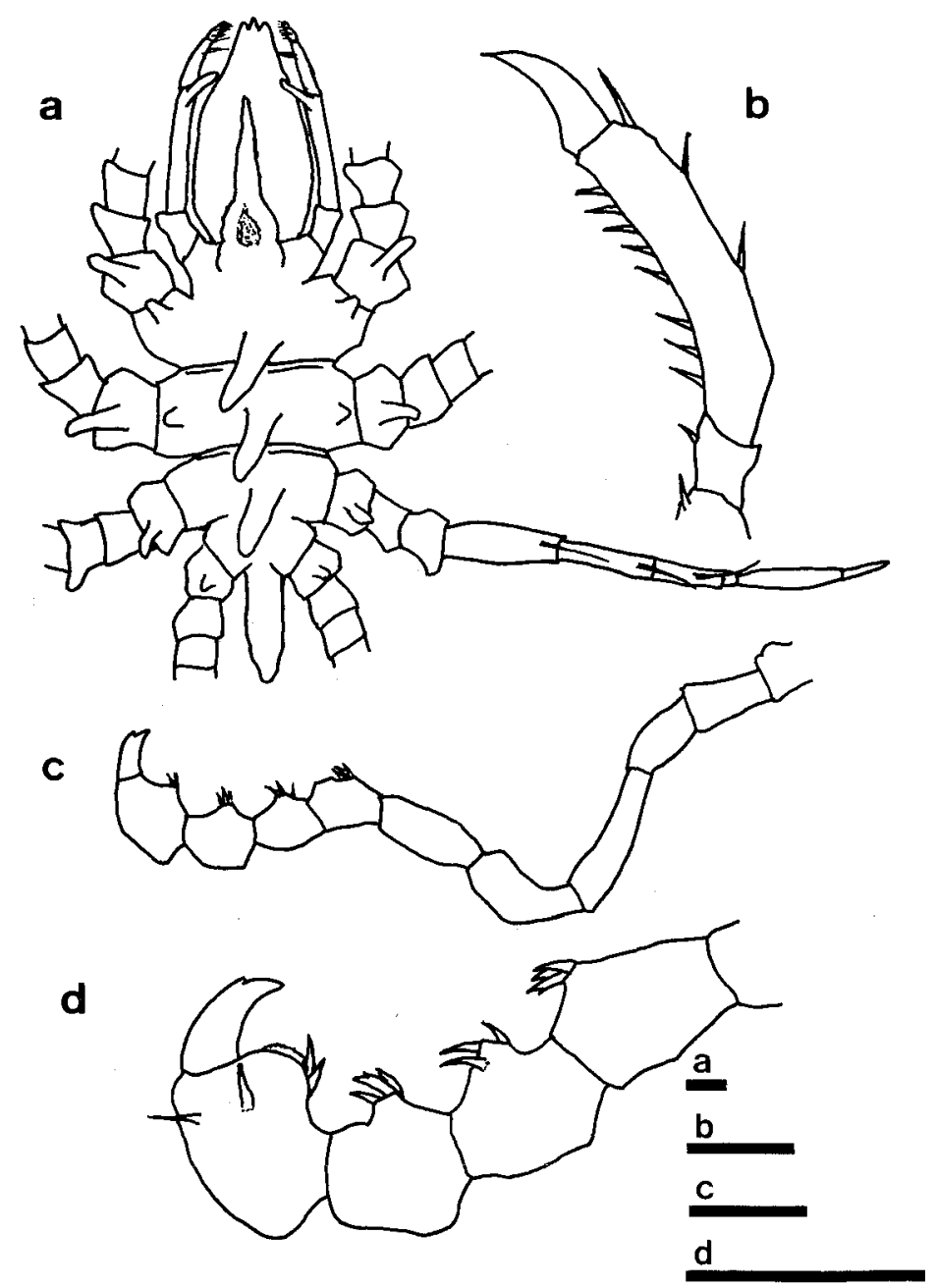

Figs. 1. Rhynchothorax mediterraneus Male. a. trunk and third right leg, dorsal view; b. terminal segments of first leg; c. right oviger; d. terminal segments of left oviger. Bars $=100 \mu \mathrm{m}$.

At first Rhynchothorax mediterraneus was described from the Mediterranean Sea, but is now known to have a much wider distribution (Fig. 2). The present record extends its distribution to the Northwest Pacific Ocean (Fig. 2), and substantiates Krapp's (1973) prediction, "They (=Rhynchothorax species) probably exist (in the Japanese waters), as there is an early Tethys connection involved...'. Indeed, there are some pycnogonid species in common between the Japanese and the Mediterranean Seas (Arnaud and Bamber, 1987).

The bathymetrical records of the present specimens are unknown, but they apparently fall within the usual range of this species $(0-200 \mathrm{~m}$; one record from $1100 \mathrm{~m}$ (Stock, 1992)). 


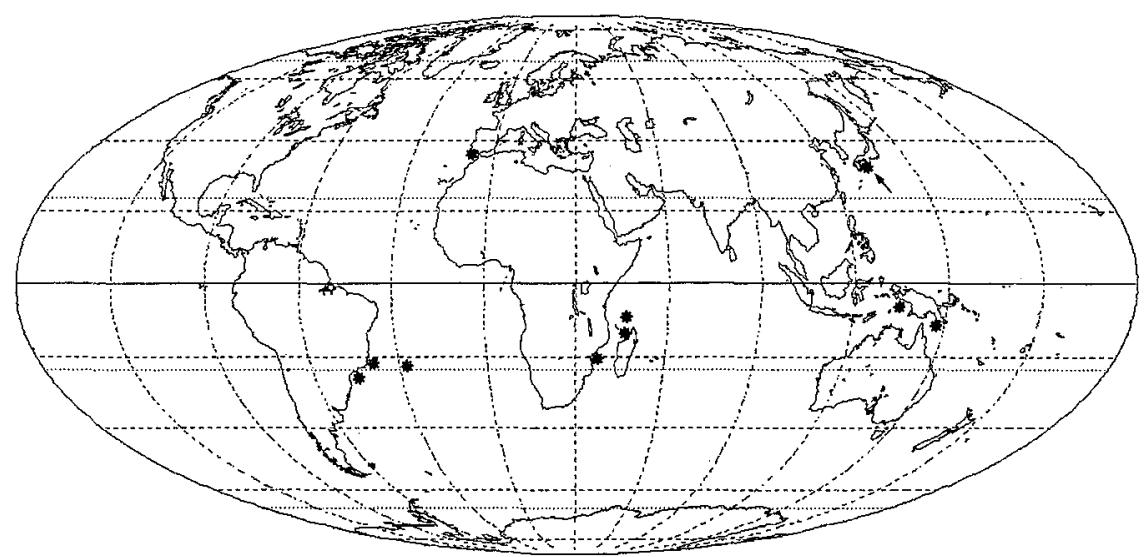

Fig. 2. Records of Rhynchothorax mediterraneus (*) outside the Mediterranean Sea. Arrow indicates the prescnt record.

\section{Acknowledgements}

The authors wish to thank Mr. Atsushi Mori, a graduate student of Seto Marine Biological Laboratory, for his kind transfer of material.

\section{References}

Arnaud, F. \& R.N. Bamber. 1987. The biology of Pycnogonida. Adv. Mar. Biol., 24: 1-96.

Arnaud, F. \& F. Krapp. 1990. The genus Rhynchothorax (Pycnogonida) in the Meditterranean Sea. Beaufortia, 41: 1-7.

Child, A.C. 1988. Pycnogonida from Aldabra Atoll. Bull. Biol. Soc. Wash., 8: 45-78.

Krapp, F. 1973. A fourth Mediterranean Rhynchothorax and remarks on the genus (Pycnogonida). Bull. Zool. Mus. Univ. Amsterdam, 3: 119-124.

Nakamura, K. \& G.A. Child. 1991. Pycnogonida from waters adjacent to Japan. Smiths. Contr. Zool., 512: $1-74$.

Stock, J.H. 1992. Pycnogonida from southern Brazil. Tijdschr. Entomol., 135: 113-139.

-. 1994. Indo-West Pacific Pycnogonida collected by some major oceanographic expeditions. Bcaufortia, 44: 17-77. 